\title{
EFFECT OF HAZARDOUS INDUSTRTIAL WASTE ON PEOPLE'S HEALTH (WITH REFERENCE TO BALLARPUR PAPER MILL INDUSTRY, BALLARPUR, DISTRICT: CHANDRAPUR)
}

\author{
Aparna S. Dhoble \\ Assistant Professor, \\ Head, Dept. of Home Science Extension \\ Sevadal Mahila Mahavidyalaya, \\ Nagpur.
}

\begin{abstract}
:
Hazardous waste from industries are the largest in countries such as India because of rapid industrialization and its impact will be recognized. Industries are the main source of environmental pollution despite their rich contribution to country's economy. Heavy pollution of ground and water bodies by industrial effluents has become a serious threat to environment. The main objectives of studies are to assess the type of pollution present due to industrial waste and to identify the effect of industrial waste on people's health. The research was carried out in Ballarpur from 100 randomly selected people with the help of schedule method. The findings shows that air pollution identified in large amount. Most of the people suffered from respiratory problems. The most common method for disposal of waste flow in rivers. The major problem always found about odour smell which affects health easily.
\end{abstract}

Keywords: pollution, industrial effluents, hazards

\section{Introduction:}

Rapid population growth and uncontrolled industrial development are seriously degrading the urban and semi-urban environment in many of the developing countries placing enormous strain on natural resources and undermining efficient and sustainable development. Industrialization leads to considerable generation of hazardous waste and in rapidly industrializing countries such as India the contribution to hazardous waste from industries are largest. Hazardous waste generation from industries is also critical due to their large geophysical, spread in the country, leading to region wide impacts. Due to liberalization policy the pace of industrialization has been accelerated, which has resulted in increasing amounts of hazardous waste every year. This along with a growing amount of municipal solid waste due to rapid urbanization and inadequate policy and technological measures, continues to remain a daunting issue of environmental concern to India. 
Environmental Protection Agency (EPA) defines "any waste or combination of wastes of a solid, liquid, contained gaseous, or semisolid from which because of its quantity, concentration or physical, chemical or infectious characteristics may cause or significantly contribute to an increase in mortality or an increase in serious irreversible or incapacitating reversible illness or pose a substantial present or potential hazards to human health or the environment when improperly treated, stored, transported or disposal of, or otherwise managed.

Industrial waste is a pollution which can be directly linked with industry, in contrast to other pollution sources. This form of pollution is one of the leading causes of pollution worldwide. Pollutants given off by various industries and factories are often considered to be one of the prime factors contributing to air, water, sound and soil pollution.

Ballarpur Industries Limited is an India based printing paper manufacturing company. It is the largest printing paper manufacturing \& exporting company operating in India. It has a strong product portfolio that includes writing, printing paper and Industrial paper.

Pollution emitted from the industries is one of the major problem for people. The emissions from various industries contain large amounts of gases such as carbon oxide, sulphur and nitrogen, among others. Various environmental and health hazards occurred and various skin disorders in individuals. A large quantity of industrial waste were found which results in rural women's health problems.

\section{Objectives:}

The main objectives of study are:

1. To assess the type of pollution present due to industrial waste.

2. To identify the effect of Industrial waste on people's health.

\section{Research Methodology:}

The present study was carried out in Ballarpur, dist. Chandrapur from 100 randomly selected people residing near Ballarpur paper mill with the help of structured interview schedule method. Collected data was tabulated and analyzed. 


\section{Results and Discussion:}

The relationship of human with the environment is necessarily symbiotic, the equilibrium between the two must be maintained at all costs. The environment is mainly a compound form of all the natural elements and living organisms, and both are essential for the future existence.

The Figure I indicates that Air pollution found in large amount i.e. 55 $\%$ due to industrial waste whereas sound pollution shows $17 \%$ and water pollution and soil pollution had $15 \%$ and $13 \%$ respectively. Fly ash is the major factor which increases the Air pollution.

An analysis of Figure II shows that most of the people suffered from respiratory problem i.e. 53 percent. About 24 percent of the respondents were of the opinion that they are facing the skin problems whereas 14 percent of the people had eye problem and very few respondents suffered from food poisoning i.e. 9 percent only. It reflects that due to Industrial waste people's health were affected.

It can be inferred from the data from Figure III that most common method for disposal of waste of Industry found to be 68 percent in river, burning method had 14 percent and dumping of Industrial waste had 18 percent respectively.

The study revealed that majority of the respondents reported due to Industry, they always faced problems like odour smell i.e. 78 percent by which their health affects (Figure IV). However, the excess of Mosquito found to be 15 percent and flies and insects increases due to wastage of Industry, i.e. 7 percent only. The people residing near paper mill faced many constraints as compared to others. Odour smell is the biggest problem for the people residing near Ballarpur paper mill.

\section{Conclusion:}

It can be concluded that due to hazardous Industrial waste of Ballarpur paper mill people faced many health problems. Air pollution found everywhere in the Ballarpur. Concentrated metals represents considerable hazard to the environment. Hence respiratory problems arise in the society. Mostly the disposal of industrial waste were dump in the river hence more 
pollution occurs. Due to odour smell found in the area people suffered a lot and faced many constraints and health affects easily.

Figure I: Types of pollution found by the respondents due to Industrial waste

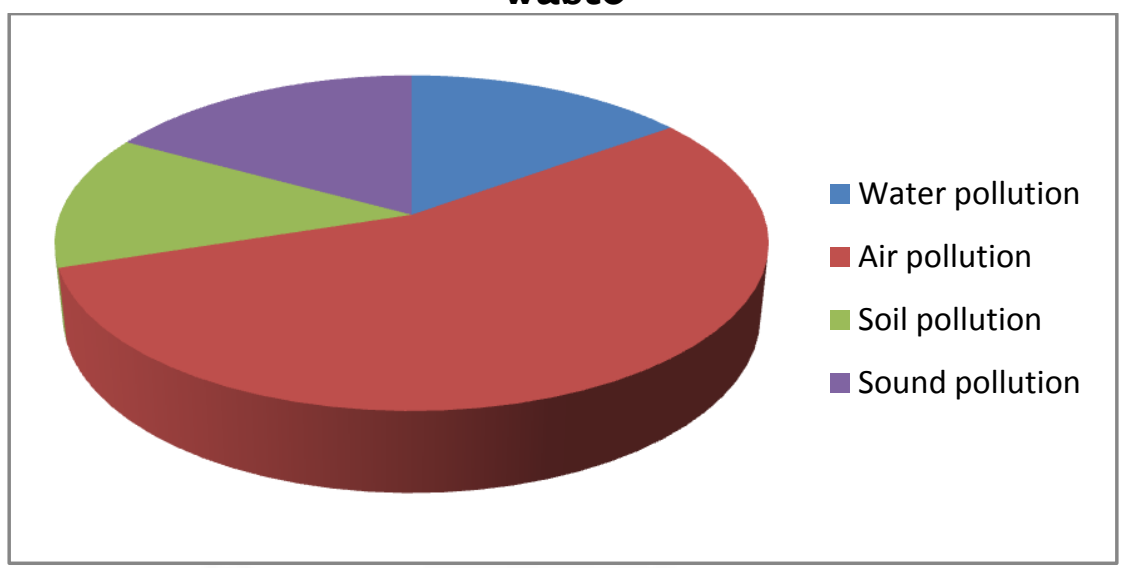

Figure II: Effect of Industrial waste on respondents's health

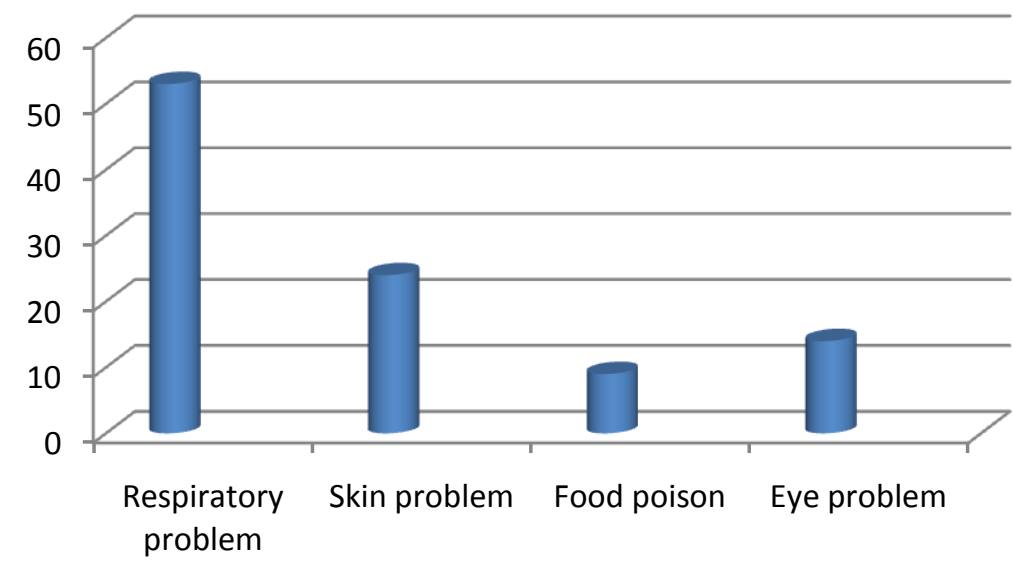

Figure III: Information about disposable of Industrial waste by the Respondents

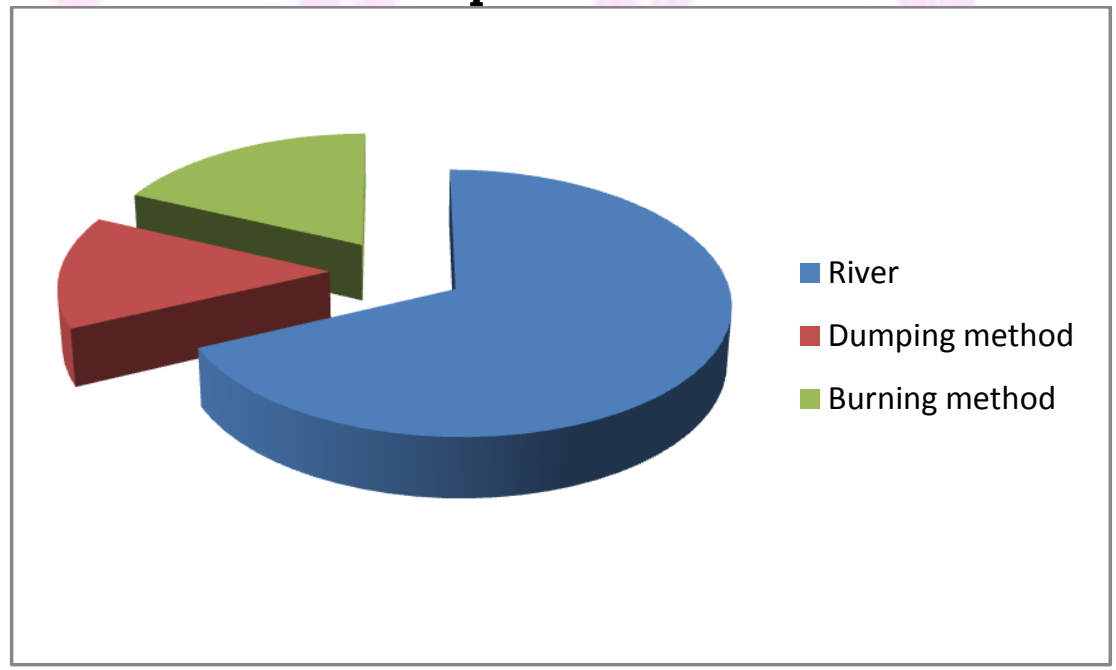




\section{Figure IV: Constraints occurred due to Industrial waste}

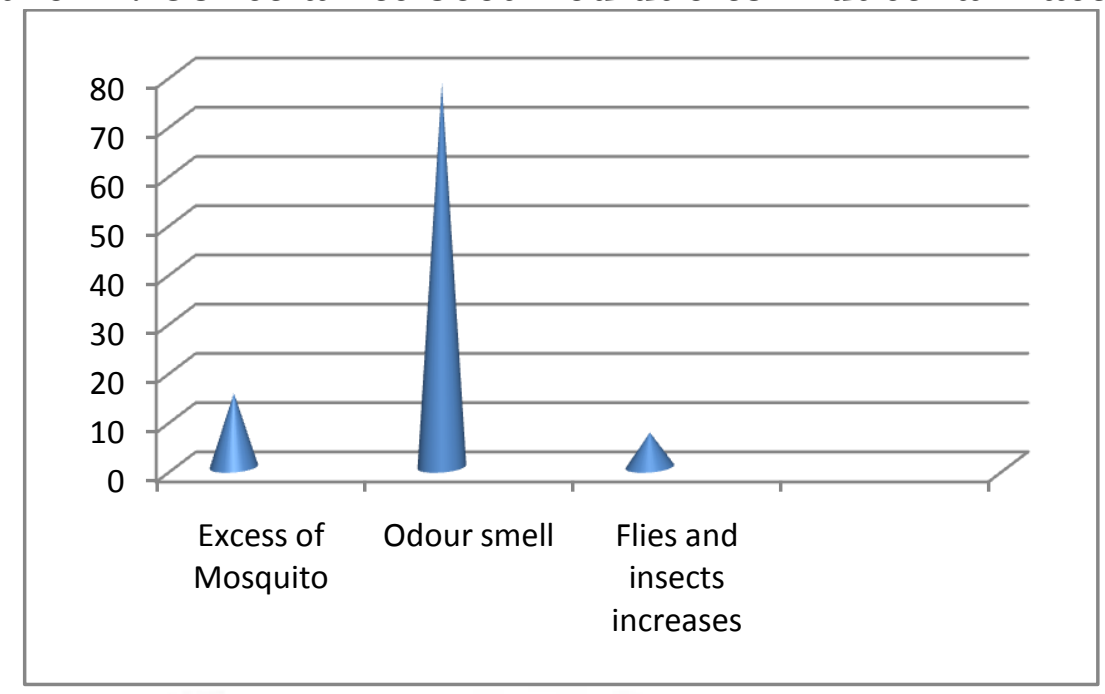

\section{References:}

- Kumar, A. \& Somashekar, R.K. (2008): 'An analysis on the elimination from industrial effluents' Environmental science and technology in India, Daya publishing house, New Delhi. Pp. 25-32.

- Bhima Rao R. (2005): "Utilisation of Kaolin Mining dumps for paper Industries" Pollution in urban industrial environment, Allied publishers private limited,New Delhi. Pp. 35-40

- Mukunda, H.S. (2011): "urban solid waste" understanding clean energy \& fuels from biomass, Wiley India Private limited, New Delhi. Pp. 241-248.

- Sawyer, C., Mccarty G. et. al. "Industrial and hazardous waste" Chemistry for environmental engineering and science, Tata Mc. Graw hill publishing company limited, New Delhi. Pp.6-7. 